\title{
Clinical Detection of Peripheral Blood Natural Killer Cell Activity
}

\author{
Yasha Wang, Wenrui Li, Guojun Huang, Yi Zhu, Qiqiang Tao*, Pinlei Lv* \\ Hainan Neology Stem Cell Anti-Aging Hospital, BoAo LeCheng International Medical Tourism Pilot Zone, Qionghai, China \\ Email: *taoqiqiang@beautech.net.cn, *lvpinlei@beautech.net.cn
}

How to cite this paper: Wang, Y.S., Li, W.R., Huang, G.J., Zhu, Y., Tao, Q.Q. and Lv, P.L. (2021) Clinical Detection of Peripheral Blood Natural Killer Cell Activity. Journal of Biosciences and Medicines, 9 , 28-36.

https://doi.org/10.4236/jbm.2021.95004

Received: April 6, 2021

Accepted: May 17, 2021

Published: May 20, 2021

Copyright $\odot 2021$ by author(s) and Scientific Research Publishing Inc. This work is licensed under the Creative Commons Attribution International License (CC BY 4.0).

http://creativecommons.org/licenses/by/4.0/

\begin{abstract}
Natural Killer (NK) cells are specific immune cells in human immune system. They have a quick effect and can exert a cytotoxic function without prior sensitization, and they show great application potential in cell-based immunotherapy, anti-infection in vivo. NK cell activity in peripheral blood can be used as one of the biomarkers of immune function response. It has a great positive guiding significance for the clinical prognosis of tumor patients, the prevention of cancer and anti-aging. The clinical detection strategies of NK cell activity in circulation mainly grouped into five types: methyl thiazolyl tetrazolium colorimetric, lactate dehydrogenase release, radionuclide labeling, flow cytometry and NK Vue cytokine release method. It has played an important role in different stages of clinical application development. This paper will make a comparative review of the above-mentioned detection strategies for the NK cell activity.
\end{abstract}

\section{Keywords}

Natural Killer Cell, Cell Activity Detection, Flow Cytometry, NK Vue

\section{Introduction}

Natural killer cells were first discovered in peripheral blood to recognize and effectively kill cancer cells in patients with leukemia [1]. Unlike T cells and B cells, NK cells do not require antigen stimulation when they play a killing effect and secrete anti-inflammatory factors. But these three kinds of cells are considered to be the effector cells of the human body's specific immunity, and are the main functional cells for monitoring malignant diseases in the body. NK cells account for about $10 \%$ to $15 \%$ of peripheral blood lymphocytes [2]. Circulating NK cells in the blood have a shorter survival time, with a half-life of only 7 - 10 days [3]. In clinical application, flow cytometry is used to detect the expression of NK cell 
surface marker $\mathrm{CD} 3-\mathrm{CD} 56+$, and the expression rate is greater than $60 \%$, which can be used in clinical practice. According to the difference in the expression density of CD56 molecules on the surface of NK cells, NK cells are divided into two subgroups, namely $\mathrm{CD} 3-\mathrm{CD} 16+\mathrm{CD} 56^{\mathrm{dim}}$ and $\mathrm{CD} 3-\mathrm{CD} 16-\mathrm{CD} 56^{\text {bright }}$. The CD3-CD16+CD56 ${ }^{\mathrm{dim}}$ subgroup accounts for more than $90 \%$ of NK cells in the peripheral blood, and the main role in the blood is cell killing, such as tumor cells, virus-infected cells and senescent cells and other abnormal cells [4] [5] [6], expressing Interleukin-12 receptor (IL-2R) with high affinity, and the CD3-CD16-CD56 bright subgroup only accounts for $10 \%$ of peripheral blood NK cells. The cells of this subgroup are mainly immunomodulatory. CD3-CD16-CD56 bright NK cells synthesize and secrete a variety of pro-inflammatory factors (interferon- $\gamma$, tumor necrosis factor- $\alpha$, etc.), and express high-affinity IL-2 receptors [7] [8]. However, mature NK cells in the blood of experimental mice express $\mathrm{CD} 27$ and CD11b, and can be divided into four types according to the density of their expression on the cell surface, namely $\mathrm{CD} 11^{\text {blow }} \mathrm{CD} 27^{\text {low }}, \mathrm{CD} 11^{\text {blow }} \mathrm{CD} 27^{\text {high }}$, $\mathrm{CD} 11 \mathrm{~b}^{\text {high }} \mathrm{CD} 27^{\text {high }}$, and $\mathrm{CD} 11 \mathrm{~b}^{\text {high }} \mathrm{CD} 27^{\text {low }}[9]$.

Researchers have found that when the number of NK cells and the activity of NK cells in the peripheral blood of the elderly (age $\geq 80$ years) are higher, the mortality rate is lower, the life time is longer, and some age-related diseases can be avoided. This phenomenon is more obvious in centenarians [10] [11] [12]. More and more evidences show that the activity and killing function of NK cells in cancer patients are significantly lower than those in normal people, such as breast cancer [13], lung cancer [14] [15] [16], ovarian cancer [17], colorectal cancer [18] [19], prostate cancer [20] [21], etc., and the peripheral blood NK cells of tumor patients will experience NK cell phenotype and functional exhaustion due to the presence of the tumor microenvironment (TME) [22] [23] [24], which cannot play the better role of NK cells. Lin et al. [25] believe that the level of NK cell activity can provide an assessment of the disease state and is related to the mechanism of evading immune surveillance. Therefore, detecting the activity of peripheral blood NK cells is particularly important for evaluating the immune function of cancer patients. There are five main types of detection of NK cell activity in clinical use, namely, tetramethylazazole blue colorimetric method, lactate dehydrogenase release method, radionuclide labeling method, flow cytometry method and NK Vue cytokine release method. These detection methods have their own advantages and disadvantages, and have played an important role in different periods of clinical application development. A comparative review of these detection methods is now made as below.

\subsection{Tetramethylazo Blue Colorimetric Method}

The Methyl Thiazolyl Tetrazolium (MTT) colorimetric method is also called the MTT method. The principle of this method is that the succinate dehydrogenase in the mitochondria of NK cells reduces the exogenous additive MTT to blue-purple crystals (Formazan), adds dimethyl sulfoxide (DMSO) to dissolve the crystal, and detects the absorbance (OD) at $490 \mathrm{~nm}$ wavelength to judge the activity of 
NK cells. The larger the OD value, the higher the activity of NK cells. As the most classic method of detecting cell activity, it is widely used in scientific research. However, the MTT method also has some drawbacks. For example, the co-cultivation time of effector cells and target cells is relatively long, and the growth rates of the two different types of cells are different, which easily causes a non-specific increase in NK cell activity, which ultimately affects the experimental results [26]. And because formazan is insoluble in water, it can only be detected after adding DMSO to dissolve it. This greatly increases the workload in clinical applications, and the repeatability of the entire experimental process is poor, which will cause a certain deviation in the accuracy of the experimental results. DMSO has certain toxicity. Once inhaled after volatilization, it will cause nausea, headache and dizziness, which is not conducive to the health of experimenters, so this method is not suitable for clinical testing.

\subsection{Lactate Dehydrogenase Release Method}

Lactic dehydrogenase (LDH) release method is one of the in vitro cytotoxicity detection methods of NK cells. The principle of this method is that LDH exists in the cytoplasm of living cells and will be released when the cell membrane is damaged. It catalyzes the formation of pyruvate from lactic acid, and reacts with tetra-salts to form formazan. Finally, the OD value is also detected by a microplate reader. This value is positively correlated with the activity of NK cells in vitro. The LDH release method has the advantages of sensitivity, simple operation, and rapidity, but there are many factors that affect the final result. For example, there is no standard and unified detection procedure between the detection platforms, and the detection results are not well repeatable. Guo Jiqiang et al. [27] compared flow cytometry and LDH method to detect the activity of NK cells in vitro, and found that after Annexin-V-FITC/PI double staining, flow cytometry can distinguish each type well. Cells, while the LDH method cannot achieve this function, and the LDH detection method has poor accuracy and relatively poor stability. At present, this method is no longer suitable for detection in clinical practice.

\subsection{Radionuclide Labeling Method}

There are three commonly used radionuclide labels, namely 51Cr, 125I-Udr and $3 \mathrm{H}-\mathrm{TdR}$ [28]. Sodium chromate $(\mathrm{Na} 251 \mathrm{CrO} 4)$ can enter the cytoplasm through the cell membrane and bind tightly to the proteins in the cytoplasm. When the 51Cr-labeled target cells are broken by the killing effect of the effector cell-NK cells, the intracellular radioactive element $51 \mathrm{Cr}$ is released. By detecting the $51 \mathrm{Cr}$ content in the cell supernatant, the NK cell activity can be calculated. The $51 \mathrm{Cr}$ release method detects NK cell activity with high accuracy. Since the detection method was invented in 1968, it has been used as the gold standard to use NK cell activity. However, this detection method has always had some problems. For example, $51 \mathrm{Cr}$ detection equipment is very expensive, and some small and me- 
dium-sized hospitals may not be able to equip it; ${ }^{51} \mathrm{Cr}$ is a radioactive element with a short half-life (27.7 days), there is a possibility of radioactive contamination, cell labeling. The efficiency and release efficiency are easily affected by time. The natural release rate of the cells after being labeled is relatively high, especially when the cells are labeled and then co-cultured for a long time. However, the killing detection after ${ }^{125} \mathrm{I}-\mathrm{Udr}$ and ${ }^{3} \mathrm{H}-\mathrm{TdR}$ is necessary Adding enzymes for further processing is expensive. The ${ }^{3} \mathrm{H}-\mathrm{TdR}$ labeling method also requires the use of a $\beta$ liquid scintillation counter, which has poor reproducibility. These three labeling methods have the possibility of radioactive contamination. Therefore, the radionuclide labeling method is no longer available used in scientific research and clinical practice.

\subsection{Flow Cytometry}

In recent years, more and more NK cell activity detection methods have been developed based on flow cytometry. Zhang et al. [29] selected K562 as the target cell, constructed a stably expressed enhanced green fluorescent protein in vitro, and labeled the target cell with Annexin V-PE/7AAD apoptotic staining. The target cells were co-cultured for 4 hours with an effective target ratio of 10:1. Cytometry to detect the apoptotic ratio of target cells is the NK cell activity, which proves that the method has good repeatability and stability. Chuang et al. [30] chose Fluorescein isothiocyanate (FITC)-labeled K562 as target cells, co-cultured for 3 hours at an effective target ratio of 100:1 and then performed flow cytometry to establish a reference interval for NK cell activity. Some scholars use fluorescent dyes to label effector NK cells and target cells (K562 cells or YAC-1 cells) in vitro, and then use propidium iodide (PI) to label dead cells to detect and determine the activity of NK cells. Method detection may affect the susceptibility of NK cells to kill and cause non-specific staining results [31] [32]. Valiathan et al. [33] evaluated a clinical study based on flow cytometry to detect the activity of NK cells. The researchers used two fluorescent dyes DiO and PI to distinguish effector cells and target cells. The green fluorescent dye DiO labeled K562 membranes. The red fluorescent dye PI added during the experiment marks the killed target cells. This method can distinguish the level of NK cell activity well, has good reproducibility, and has the advantages of time-saving, and can be used flexibly in clinical laboratories Adjustment.

\subsection{NK Vue Cytokine Release Method}

The NK Vue cytokine release method is a kit specially developed by South Korea NK MAX for detecting the activity of peripheral blood NK cells in vitro. The basic principle is to use the human recombinant protein Promaca to stimulate NK cells in peripheral blood in vitro to make them secrete a large amount of IFN- $\gamma$, ELISA method to detect the content of IFN- $\gamma$, with this value to reflect the activity of human peripheral blood NK cells [18]. Jobin G et al. [19] used this method to detect and analyze the relationship between NK cell activity and high-risk co- 
lorectal cancer patients, and the results showed a negative predictive value of 99.4\%, and subjects with low NK cell activity had a higher risk of colorectal cancer. Subjects with NK cell activity were 10 times higher. Barkin J et al. [21] found that this method was used to detect NK cell activity, and the results showed that subjects with low NK cell activity values were more likely to have positive results in prostate cancer biopsy. Tae BS et al. [34] also proved that the NK cell activity detected by this technology can help screen patients who need a biopsy to diagnose prostate cancer with high accuracy. Many clinical research institutions have adopted this technology for clinical research on NK cell activity detection (NCT02291198, NCT03422120, NCT02661776), and it has good applications in colorectal cancer pre-screening and postoperative immune function judgment for head and neck cancer. This method is used in the ongoing immune cell therapy project of the oncology department of our hospital to assist in the assessment of the patient's immune function status, and to provide a reference for clinical treatment as a basis for follow-up (research results have not yet been published). However, due to many personal life reasons or consumption of drugs, etc., it will affect the individual's NK cell activity products, which will bias the final test results, such as stress and sleep disorders [35] [36], take steroid drugs [35] [36] [37] [38], proton pump inhibitors [39], long-term smoking [40], drinking [41] and foods rich in zinc and selenium [42] [43], etc., will temporarily decrease or increase the value of NK cell activity high. Therefore, the clinical application of this method needs to be further verified, and the influence of more exclusionary factors needs to be considered.

\section{Discussion}

NK cell activity can directly reflect the functional state of human immune cells, and the immune functional state has a very strong correlation with the occurrence and development of cancer. Malignant tumors in the human body [20] [44] [45], stress and lack of sleep [35] [36], pregnancy [46] [47], autoimmune diseases [48], the activity of NK cells in the peripheral blood will be continuously low, so it is particularly important to detect the activity of peripheral blood NK cells in vitro.

The clinically used detection of NK cell activity in peripheral blood must have good repeatability, operability and stability of results, and be able to be widely used in large-scale applications. There are 5 conventional detection methods, namely MTT colorimetric method, LDH release method, radionuclide labeling method, flow cytometry and NK Vue cytokine release method. Among them, the first three detection methods have more shortcomings in the use process. Obviously, the operation is more complicated, the time is long, the reproducibility of the experimental results is poor, and it may cause certain physical injury to the operator and other obvious shortcomings, thus limiting the clinical promotion and application of these three detection methods. Flow cytometry is a more commonly used clinical method to detect NK cell activity in recent years, but 
there is no unified operating procedure. In the selection of the efficiency target ratio, the co-cultivation time of effector cells and target cells, the staining time of fluorescent dyes and the incubation time of antibodies, there are large differences in the operating methods given by each manufacturer, and further optimization is needed. And can achieve better repeatability and operability. The NK Vue cytokine release method is an in vitro experimental method invented in recent years to assess the state of human immune function. It has demonstrated good operability, repeatability and accuracy in clinical trials and studies that have been completed. The whole operation process only needs to draw $1 \mathrm{~mL}$ of peripheral blood, and there is no need to separate PBMC for subsequent experiments, which can more intuitively reflect the real immune function status of the human body. However, due to factors such as diet or personal living habits that affect the body's NK cell activity, the clinical application of this method may need to be further verified for its accuracy.

\section{Conclusion}

Although flow cytometry is currently used in clinical applications to detect NK cell activity, and different fluorescent dyes are added to label effective target cells, there may be differences between the experimental results, which should be worthy of attention. The emerging detection method-NK Vue cytokine release method is still in the initial stage of clinical application, and the accuracy of the detection method needs further clinical verification.

\section{Acknowledgements}

This work is supported by CEO of Neology Zhu Yi and Business director of Neology Huang Guojun. The director of hospital Tao Qiqiang kindly gives advices to select the topic, Li Wenrui assists to search papers related to NK cell activity detection. Wang Yasha and Lv Pinlei write the manuscript. Tao Qiqiang and Lv Pinlei supervise the manuscript.

\section{Conflicts of Interest}

The authors declare no conflicts of interest regarding the publication of this paper.

\section{References}

[1] Kiessling, R., Klein, E. and Wigzell, H. (1975) "Natural" Killer Cells in the Mouse. I. Cytotoxic Cells with Specificity for Mouse Moloney Leukemia Cells. Specificity and Distribution According to Genotype. European Journal of Immunology, 5, 112-117. https://doi.org/10.1002/eji.1830050208

[2] Tarazona, R., Lopez-Sejas, N., Guerrero, B., et al. (2020) Current Progress in NK cell Biology and NK Cell-Based Cancer Immunotherapy. Cancer Immunology, Immunotherapy, 69, 879-899. https://doi.org/10.1007/s00262-020-02532-9

[3] Campbell, K.S. and Hasegawa, J. (2013) Natural Killer Cell Biology: An Update and Future Directions. The Journal of Allergy and Clinical Immunology, 132, 536-544. 
https://doi.org/10.1016/j.jaci.2013.07.006

[4] Dahlberg, C.I., Sarhan, D., Chrobok, M., et al. (2015) Natural Killer Cell-Based Therapies Targeting Cancer: Possible Strategies to Gain and Sustain Anti-Tumor Activity. Frontiers in Immunology, 6, 605. https://doi.org/10.3389/fimmu.2015.00605

[5] Krizhanovsky, V., Yon, M., Dickins, R.A., et al. (2008) Senescence of Activated Stellate Cells Limits Liver Fibrosis. Cell, 134, 657-667. https://doi.org/10.1016/j.cell.2008.06.049

[6] Hueber, B., Curtis 2nd, A.D., Kroll, K., et al. (2020) Functional Perturbation of Mucosal Group 3 Innate Lymphoid and Natural Killer Cells in Simian-Human Immunodeficiency Virus/Simian Immunodeficiency Virus-Infected Infant Rhesus Macaques. Journal of Virology, 94, No. 5. https://doi.org/10.1128/JVI.01644-19

[7] Frutoso, M. and Mortier, E. (2019) NK Cell Hyporesponsiveness: More Is Not Always Better. International Journal of Molecular Sciences, 20, 4514. https://doi.org/10.3390/ijms20184514

[8] Hodgins, J.J., Khan, S.T., Park, M.M., et al. (2019) Killers 2.0: NK Cell Therapies at the Forefront of Cancer Control. The Journal of Clinical Investigation, 129, 3499-3510. https://doi.org/10.1172/JCI129338

[9] Chiossone, L., Chaix, J., Fuseri, N., et al. (2009) Maturation of Mouse NK Cells Is a 4-Stage Developmental Program. Blood, 113, 5488-5496.

https://doi.org/10.1182/blood-2008-10-187179

[10] Sansoni, P., Cossarizza, A., Brianti, V., et al. (1993) Lymphocyte Subsets and Natural Killer Cell Activity in Healthy Old People and Centenarians. Blood, 82, 2767-2773. https://doi.org/10.1182/blood.V82.9.2767.2767

[11] Le Garff-Tavernier, M., Béziat, V., Decocq, J., et al. (2010) Human NK Cells Display Major Phenotypic and Functional Changes over the Life Span. Aging Cell, 9, 527-535. https://doi.org/10.1111/j.1474-9726.2010.00584.x

[12] Sansoni, P., Vescovini, R., Fagnoni, F., et al. (2008) The Immune System in Extreme Longevity. Experimental Gerontology, 43, 61-65.

https://doi.org/10.1016/j.exger.2007.06.008

[13] Dewan, M.Z., Takada, M., Terunuma, H., et al. (2009) Natural Killer Activity of Peripheral-Blood Mononuclear Cells in Breast Cancer Patients. Biomedicine \& Pharmacotherapy, 63, 703-706. https://doi.org/10.1016/j.biopha.2009.02.003

[14] Lin, C.C., Kuo, Y.C., Huang, W.C., et al. (1987) Natural Killer Cell Activity in Lung Cancer Patients. Chest, 92, 1022-1024. https://doi.org/10.1378/chest.92.6.1022

[15] Bobek, V., Boubelik, M., Fiserová, A., et al. (2005) Anticoagulant Drugs Increase Natural Killer Cell Activity in Lung Cancer. Lung Cancer (Amsterdam, Netherlands), 47, 215-223. https://doi.org/10.1016/j.lungcan.2004.06.012

[16] Choi, S.I., Lee, S.H., Park, J.Y., et al. (2019) Clinical Utility of a Novel Natural Killer Cell Activity Assay for Diagnosing Non-Small Cell Lung Cancer: A Prospective Pilot Study. OncoTargets and Therapy, 12, 1661-1669.

https://doi.org/10.2147/OTT.S194473

[17] Lutgendorf, S.K., Sood, A.K., Anderson, B., et al. (2005) Social Support, Psychological Distress, and Natural Killer Cell Activity in Ovarian Cancer. Journal of Clinical Oncology, 23, 7105-7113. https://doi.org/10.1200/JCO.2005.10.015

[18] Lee, S.B., Cha, J., Kim, I.K., et al. (2014) A High-Throughput Assay of NK Cell Activity in Whole Blood and Its Clinical Application. Biochemical and Biophysical Research Communications, 445, 584-590. https://doi.org/10.1016/j.bbrc.2014.02.040 
[19] Jobin, G., Rodriguez-Suarez, R. and Betito, K. (2017) Association between Natural Killer Cell Activity and Colorectal Cancer in High-Risk Subjects Undergoing Colonoscopy. Gastroenterology, 153, 980-987.

https://doi.org/10.1053/j.gastro.2017.06.009

[20] Koo, K.C., Shim, D.H., Yang, C.M., et al. (2013) Reduction of the CD16 ${ }^{-}$CD56 bright NK Cell Subset Precedes NK Cell Dysfunction in Prostate Cancer. PLoS ONE, 8, e78049. https://doi.org/10.1371/journal.pone.0078049

[21] Barkin, J., Rodriguez-Suarez, R. and Betito, K. (2017) Association between Natural Killer Cell Activity and Prostate Cancer: A Pilot Study. The Canadian Journal of Urology, 24, 8708-8713.

[22] Bi, J. and Tian, Z. (2017) NK Cell Exhaustion. Frontiers in Immunology, 8, 760. https://doi.org/10.3389/fimmu.2017.00760

[23] Zhang, Q., Bi, J., Zheng, X., et al. (2018) Blockade of the Checkpoint Receptor TIGIT Prevents NK Cell Exhaustion and Elicits Potent Anti-Tumor Immunity. Nature Immunology, 19, 723-732. https://doi.org/10.1038/s41590-018-0132-0

[24] Merino, A.M., Kim, H., Miller, J.S. and Cichocki, F. (2020) Unraveling Exhaustion in Adaptive and Conventional NK Cells. Journal of Leukocyte Biology, 108, 1361-1368. https://doi.org/10.1002/JLB.4MR0620-091R

[25] Lin, C.-F., Lin, C.-M., Lee, K.-Y., et al. (2017) Escape from IFN- $\gamma$-Dependent Immunosurveillance in Tumorigenesis. Journal of Biomedical Science, 24, Article No. 10. https://doi.org/10.1186/s12929-017-0317-0

[26] Gu, Z.M., Ma, Z.S., An, J.H., et al. (2003) Determination of NK Cytotoxicity by Improved MTT Assay. Journal of Jilin University (Medical Edition), 29, 119-120.

[27] Guo, J.Q., Han, Y.P., Jia, Y., et al. (2015) Comparison of NK Cell Activity by Flow Cytometry and LDH Assay. The 10th National Congress of Immunology, Beijing, 15 May 2015, 1.

[28] Xie, Q., Wu, H.S., Fan, X.Y., et al. (1987) Comparative Study on the Determination of NK Activity by $3 \mathrm{H}-\mathrm{TdR}, 51 \mathrm{Cr}, 125 \mathrm{I}-\mathrm{UDR}$ Release Test. Shanghai Journal of Immunology, No. 6, 351-354.

[29] Zhang, J., Wang, Y., Wu, L., et al. (2017) Application of an Improved Flow Cytometry-Based NK Cell Activity Assay in Adult Hemophagocytic Lymphohistiocytosis. International Journal of Hematology, 105, 828-834. https://doi.org/10.1007/s12185-017-2195-3

[30] Chung, H.J., Park, C.J., Lim, J.H., et al. (2010) Establishment of a Reference Interval for Natural Killer Cell Activity through Flow Cytometry and Its Clinical Application in the Diagnosis of Hemophagocytic Lymphohistiocytosis. International Journal of Laboratory Hematology, 32, 239-247.

https://doi.org/10.1111/j.1751-553X.2009.01177.x

[31] Godoy-Ramirez, K., Franck, K. and Gaines, H. (2000) A Novel Method for the Simultaneous Assessment of Natural Killer Cell Conjugate Formation and Cytotoxicity at the Single-Cell Level by Multi-Parameter Flow Cytometry. Journal of Immunological Methods, 239, 35-44. https://doi.org/10.1016/S0022-1759(00)00161-7

[32] Wagner, N., Wagner, K.D., Xing, Y., et al. (2004) The Major Podocyte Protein Nephrin Is Transcriptionally Activated by the Wilms' Tumor Suppressor WT1. Journal of the American Society of Nephrology, 15, 3044-3051. https://doi.org/10.1097/01.ASN.0000146687.99058.25

[33] Valiathan, R., Lewis, J.E., Melillo, A.B., et al. (2012) Evaluation of a Flow Cytometry-Based Assay for Natural Killer Cell Activity in Clinical Settings. Scandinavian Journal of Immunology, 75, 455-462. 
https://doi.org/10.1111/j.1365-3083.2011.02667.x

[34] Tae, B.S., Jeon, B.J., Lee, Y.H., et al. (2020) Can Natural Killer Cell Activity Help Screen Patients Requiring a Biopsy for the Diagnosis of Prostate Cancer? International Brazilian Journal of Urology, 46, 244-252.

https://doi.org/10.1590/s1677-5538.ibju.2019.0268

[35] Witek-Janusek, L., Gabram, S. and Mathews, H.L. (2007) Psychologic Stress, Reduced NK Cell Activity, and Cytokine Dysregulation in Women Experiencing Diagnostic Breast Biopsy. Psychoneuroendocrinology, 32, 22-35. https://doi.org/10.1016/j.psyneuen.2006.09.011

[36] Irwin, M., McClintick, J., Costlow, C., et al. (1996) Partial Night Sleep Deprivation Reduces Natural Killer and Cellular Immune Responses in Humans. The FASEB Journal, 10, 643-653. https://doi.org/10.1096/fasebj.10.5.8621064

[37] Crosbie, J., Magnussen, M., Dornbier, R., et al. (2013) Statins Inhibit Proliferation and Cytotoxicity of a Human Leukemic Natural Killer Cell Line. Biomarker Research, 1, Article No. 33. https://doi.org/10.1186/2050-7771-1-33

[38] Vitale, C., Chiossone, L., Cantoni, C., et al. (2004) The Corticosteroid-Induced Inhibitory Effect on NK Cell Function Reflects Down-Regulation and/or Dysfunction of Triggering Receptors Involved in Natural Cytotoxicity. European Journal of Immunology, 34, 3028-3038. https://doi.org/10.1002/eji.200425418

[39] Alkim, H., Unal, S., Okur, H. and Imir, T. (2008) Omeprazole Inhibits Natural Killer Cell Functions. Digestive Diseases and Sciences, 53, 347-351.

https://doi.org/10.1007/s10620-007-9869-2

[40] Jung, Y.S., Park, J.H., Park, D.I., et al. (2020) Impact of Smoking on Human Natural Killer Cell Activity: A Large Cohort Study. Journal of Cancer Prevention, 25, 13-20. https://doi.org/10.15430/JCP.2020.25.1.13

[41] Ben-Eliyahu, S., Page, G.G., Yirmiya, R. and Taylor, A.N. (1996) Acute Alcohol Intoxication Suppresses Natural Killer Cell Activity and Promotes Tumor Metastasis. Nature Medicine, 2, 457-460. https://doi.org/10.1038/nm0496-457

[42] Haase, H. and Rink, L. (2014) Zinc Signals and Immune Function. BioFactors (OXford, England), 40, 27-40. https://doi.org/10.1002/biof.1114

[43] Duntas, L.H. and Benvenga, S. (2015) Selenium: An Element for Life. Endocrine, 48, 756-775. https://doi.org/10.1007/s12020-014-0477-6

[44] Santos, M.F., Mannam, V.K., Craft, B.S., et al. (2014) Comparative Analysis of Innate Immune System Function in Metastatic Breast, Colorectal, and Prostate Cancer Patients with Circulating Tumor Cells. Experimental and Molecular Pathology, 96, 367-374. https://doi.org/10.1016/j.yexmp.2014.04.001

[45] Viel, S., Charrier, E., Marçais, A., et al. (2013) Monitoring NK Cell Activity in Patients with Hematological Malignancies. Oncoimmunology, 2, e26011.

https://doi.org/10.4161/onci.26011

[46] Hansen, K.A., Opsahl, M.S., Nieman, L.K., et al. (1992) Natural Killer Cell Activity from Pregnant Subjects Is Modulated by RU 486. American Journal of Obstetrics and Gynecology, 166, 87-90. https://doi.org/10.1016/0002-9378(92)91835-X

[47] Sharma, S. (2014) Natural Killer Cells and Regulatory T Cells in Early Pregnancy Loss. The International Journal of Developmental Biology, 58, 219-229. https://doi.org/10.1387/ijdb.140109ss

[48] Lünemann, A., Tackenberg, B., DeAngelis, T., et al. (2011) Impaired IFN- $\gamma$ Production and Proliferation of NK Cells in Multiple Sclerosis. International Immunology, 23, 139-148. https://doi.org/10.1093/intimm/dxq463 